\title{
High-Performance Flexible Hybrid Field-Effect Transistors Based on Cellulose Fiber Paper
}

\author{
Elvira Fortunato, Nuno Correia, Pedro Barquinha, Luís Pereira, Gonçalo Gonçalves, and Rodrigo Martins
}

\begin{abstract}
In this letter, we report for the first time the use of a sheet of cellulose-fiber-based paper as the dielectric layer used in oxide-based semiconductor thin-film field-effect transistors (FETs). In this new approach, we are using the cellulosefiber-based paper in an "interstrate" structure since the device is built on both sides of the cellulose sheet. Such hybrid FETs present excellent operating characteristics such as high channel saturation mobility ( $\left.>30 \mathrm{~cm}^{2} / \mathrm{Vs}\right)$, drain-source current on/off modulation ratio of approximately $10^{4}$, near-zero threshold voltage, enhancement n-type operation, and subthreshold gate voltage swing of 0.8 V/decade. The cellulose-fiber-based paper FETs' characteristics have been measured in air ambient conditions and present good stability, after two months of being processed. The obtained results outpace those of amorphous Si thin-film transistors (TFTs) and rival with the same oxide-based TFTs produced on either glass or crystalline silicon substrates. The compatibility of these devices with large-scale/large-area deposition techniques and lowcost substrates as well as their very low operating bias delineates this as a promising approach to attain high-performance disposable electronics like paper displays, smart labels, smart packaging, RFID, and point-of-care systems for self-analysis in bioapplications, among others.
\end{abstract}

Index Terms-Cellulose fibers, oxide field-effect transistor (FET), RF magnetron sputtering, thin films.

\section{INTRODUCTION}

$\mathbf{N}$ OWADAYS, there is a strong interest in the use of biopolymers for electronic applications, mainly driven by low-cost applications. Cellulose is the Earth's major biopolymer and is of tremendous global economic importance. The possibility to integrate electronic and optoelectronic functions within the production methods of the paper industry is therefore of current interest to enhance and to add new functionalities to conventional cellulose-fiber-based paper. To fulfill these demands, materials and methods should be developed for cheap and mass production. An example is printed electronics using ink-jet technology [1]-[3] or even classical printing methods

Manuscript received March 18, 2008; revised June 7, 2008. This work was supported in part by the Fundação para a Ciência e a Tecnologia (FCT), Ministério da Ciência, Tecnologia e Ensino Superior (MCTES), under Project PTDC/CTM/73943/2006 and Project PTDC/EEA-ELC/64975/2006 and in part by the Electronic and Telecommunications Research Institute (ETRI), Korea. The work of P. Barquinha was supported by FCT under Fellowship SFRH/BD/17970/2004. The work of G. Gonçalves was supported by FCT under Fellowship SFRH/BD/27313/2006. The review of this letter was arranged by Editor A. Nathan.

The authors are with the Materials Science Department, CENIMAT/I3N and CEMOP/UNINOVA, Faculty of Sciences and Technology, New University of Lisbon, Campus de Caparica, 2829-516 Caparica, Portugal (e-mail: elvira.fortunato@fct.unl.pt).

Color versions of one or more of the figures in this letter are available online at http://ieeexplore.ieee.org.

Digital Object Identifier 10.1109/LED.2008.2001549 like reel-to-reel processing [4]. Some reports have been presented recently using cellulose-based paper as either a substrate for physical support of processing devices like organic thin-film transistors (TFTs) [5], logic circuits [6], and electrochromic displays [7] or as an active media in thin-film flexible Li batteries [8], originating what we call paper electronics as opposed to electronic paper (e-paper) [9].

In this letter, we report for the first time the use of a conventional sheet of cellulose-fiber-based paper simultaneously as the substrate and the dielectric layer in oxide field-effect transistors (FETs), fully processed at room temperature.

In this new device approach, we are using the cellulosefiber-based paper as an "interstrate" structure since the device is built on both sides of the cellulose sheet: the gate electrode, based on a transparent conductive oxide, is deposited on one side, and on the other is the active semiconductor, to be used as the channel layer, and the highly conductive drain and source regions [10]-[12].

\section{EXPERIMENTAL DETAILS}

The proposed FETs were produced using two different cellulose-fiber-based papers (with different finishing surfaces, A and B; see Fig. 1), acting as the gate dielectric, without any kind of surface treatment. On one side of the paper sheet, a 40-nm-thick GIZO $\left(\mathrm{Ga}_{2} \mathrm{O}_{3}-\mathrm{In}_{2} \mathrm{O}_{3}-\mathrm{ZnO} ; 1: 2: 1 \%\right.$ mol) layer (the active oxide semiconductor) was deposited by RF magnetron sputtering, at room temperature, in a Pfeiffer Vacuum Classic 500 system. The aluminum source and drain regions were deposited afterward by e-beam evaporation $(180 \mathrm{~nm})$ over the patterned semiconductor region. On the other side of the paper sheet, an IZO $\left(\mathrm{In}_{2} \mathrm{O}_{3}-\mathrm{ZnO} ; 5: 2 \mathrm{~mol} \%\right)$ film $(160 \mathrm{~nm})$ was deposited by RF sputtering at room temperature, to serve as the gate electrode. The paper sheet works simultaneously as the substrate and the device dielectric layer. Fig. 2 shows a schema of the proposed device configuration, illustrating the different layers and the corresponding thickness.

The FETs were electrically characterized in air, at room temperature, and in the dark using a Cascade Microtech M150 microprobe station connected to a semiconductor parameter analyzer (Agilent 4155C) controlled by the Metrics ICS software. The films' thickness was measured with a Sloan Tech Dektak surface profilometer. The surface characterization of the cellulose paper was done by scanning electron microscopy (SEM) using SU-70 FE from Hitachi. The electrical characteristics of the oxide films were determined from Hall effect measurements using the Van der Pauw geometry (Biorad HL5500) at a constant magnetic field of $0.5 \mathrm{~T}$. 


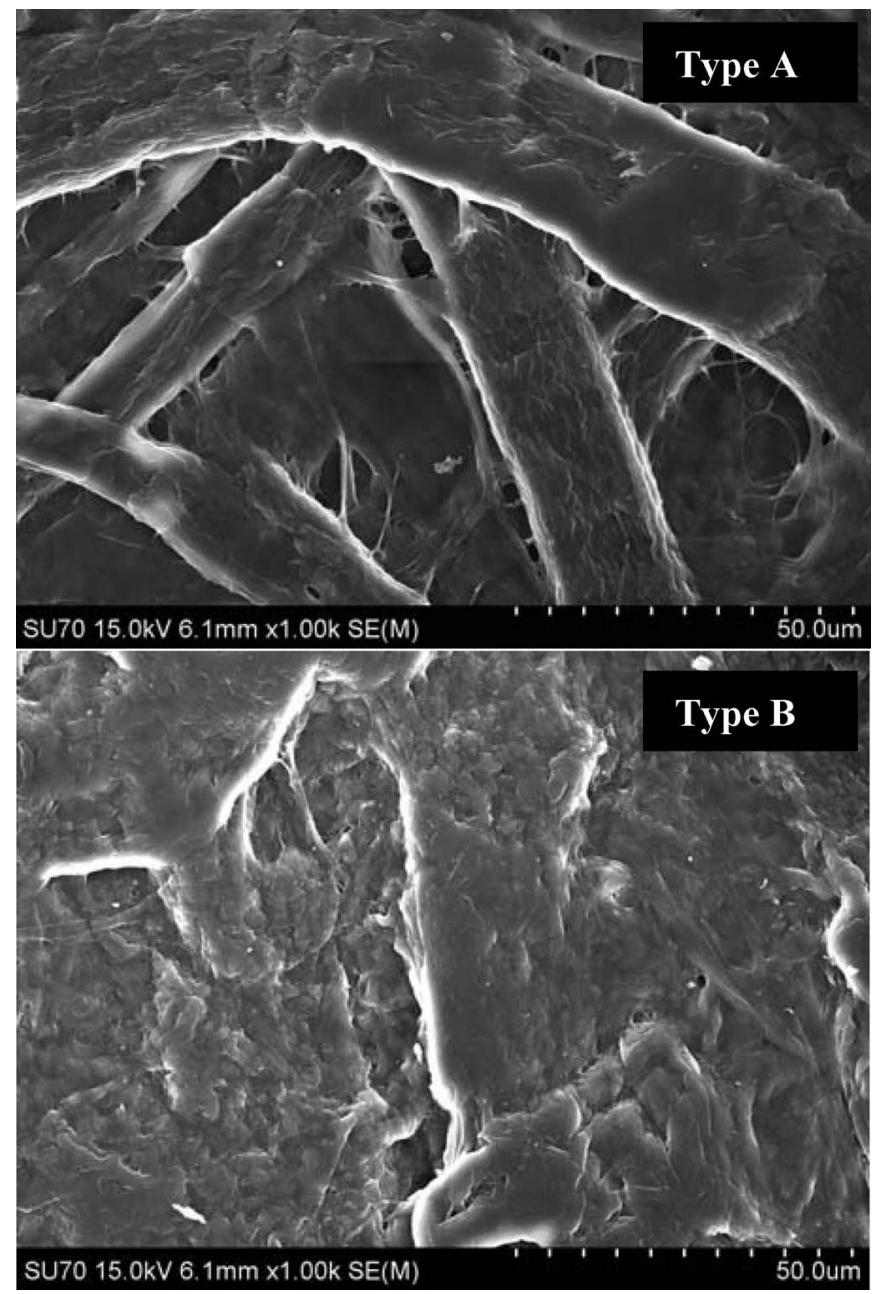

Fig. 1. SEM images showing the type of microstructure exhibited by cellulose-paper-based fibers: type A presents a higher porosity, while type B shows a more compact structure.

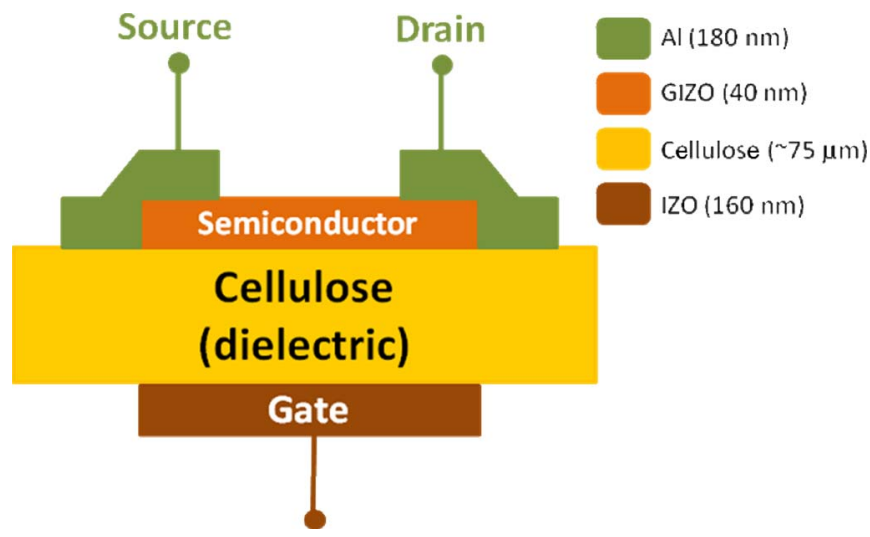

Fig. 2. Schema of the FET structure using the cellulose sheet as the gate dielectric.

\section{RESUlTS AND DISCUSSION}

To evaluate the electrical properties of the cellulose fibers as well as to determine the effectiveness of their coating, an IZO thin film (gate electrode) was deposited on top of the two different substrates. Electrical resistivity and Hall mobility measurements were carried out at room temperature. The obtained values are presented in Table I and compared to
TABLE I

COMPARISON OF THE ELECTRICAL PROPERTIES OF AMORPHOUS IZO Thin FILMS DEPOSITED ON DifFERENT SUBSTRATES

\begin{tabular}{lcc}
\hline \hline \multicolumn{1}{c}{ Substrate } & $\begin{array}{c}\text { Resistivity } \\
(\Omega \mathrm{cm})\end{array}$ & $\begin{array}{c}\text { Hall mobility } \\
\left(\mathrm{cm}^{2} / \mathrm{Vs}\right)\end{array}$ \\
\hline Soda-lime glass & $4.0 \times 10^{-4}$ & 35.0 \\
Cellulose fiber Type A & $1.0 \times 10^{-3}$ & 6.7 \\
Cellulose fiber Type B & $1.3 \times 10^{-3}$ & 10.0 \\
\hline
\end{tabular}

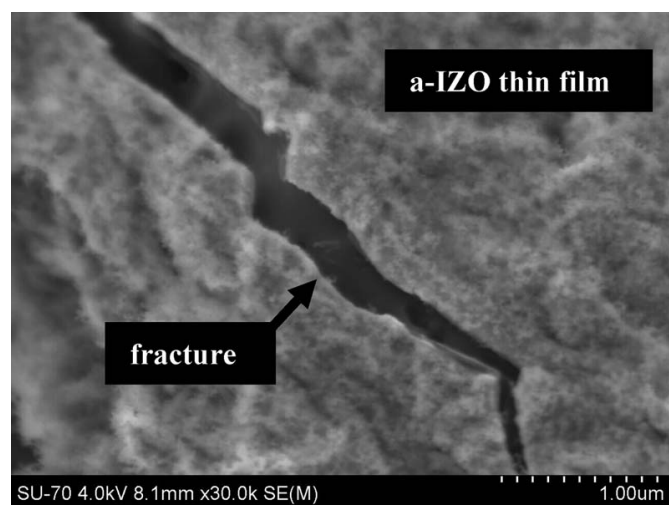

Fig. 3. IZO crack due to the different thermal expansion coefficient of IZO and the cellulose fiber, revealing the high adhesion coefficient of the oxide material to the cellulose fiber. The film was continuously deposited.

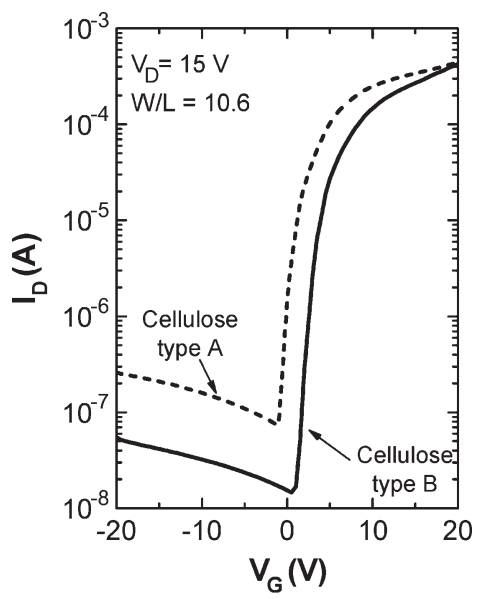

Fig. 4. $I_{D}-V_{G}$ transfer characteristics obtained at $V_{D}=15 \mathrm{~V}$ (saturation region) for GIZO FETs using two types of cellulose fiber as dielectric layers, fully produced at room temperature.

those obtained for IZO deposited on soda-lime glass. The IZO films deposited on cellulose paper substrates show electrical performances that are slightly inferior to the ones deposited on glass substrates. The resistivity increases about 2.5 times with a significant decrease associated to the Hall mobility, from $35 \mathrm{~cm}^{2} / \mathrm{Vs}$ to around $8 \mathrm{~cm}^{2} / \mathrm{Vs}$ on the average, mainly due to the high surface roughness of the cellulose fiber paper. Similar results have been obtained on polymeric substrates [13].

To observe the cellulose fiber surface coverage by the IZO film, a high-magnification SEM was performed (30 k). Fig. 3 shows a fracture that occurred due to the overheating induced by the microscope electron beam. The film presents an amorphous structure and covers all the free surface of the cellulose fibers.

Fig. 4 shows the transfer characteristics of two typical GIZO FETs, with $\mathrm{W} / \mathrm{L}=10.6$, in the saturation region $\left(V_{D}=15 \mathrm{~V}\right)$ 
TABLE II

COMParison of THE Electrical Properties of GIZO-BASEd FETS With DifFERENT DiELECTRIC MATERIALS

\begin{tabular}{lcccc}
\hline \hline $\begin{array}{c}\text { Substrate } \\
(\text { dielectric })\end{array}$ & $\begin{array}{c}\mu_{\text {sat }} \\
\left(\mathrm{cm}^{2} / \mathrm{Vs}\right)\end{array}$ & $\begin{array}{c}\mathrm{V}_{\text {th }} \\
(\mathrm{V})\end{array}$ & $\mathrm{I}_{\mathrm{ON}} / \mathrm{I}_{\mathrm{OFF}}$ & $\begin{array}{c}\mathrm{S} \\
(\mathrm{V} / \mathrm{dec})\end{array}$ \\
\hline $\mathrm{Si} / \mathrm{SiO}_{2}$ & 30 & +1.8 & $8.0 \times 10^{8}$ & 0.4 \\
Cellulose Type A & 30 & -0.6 & $5.9 \times 10^{3}$ & 0.8 \\
Cellulose Type B & 34 & +1.9 & $2.9 \times 10^{4}$ & 0.8 \\
\hline
\end{tabular}

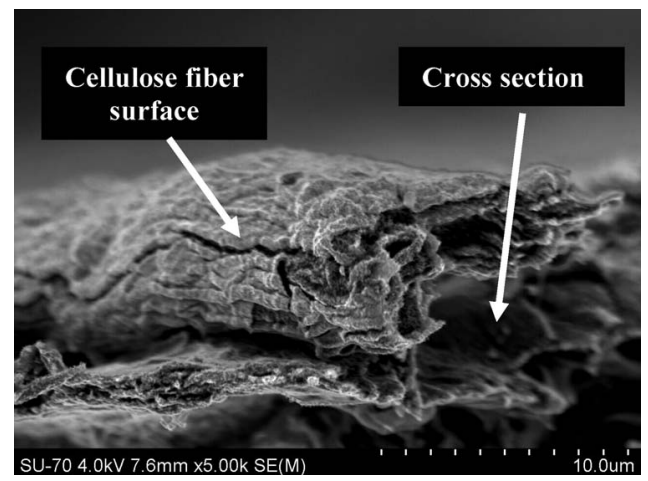

Fig. 5. SEM image of a cross section of a cellulose fiber, revealing the internal morphology

using the two types of cellulose-based fiber as the dielectric layer. The saturation mobility $\left(\mu_{\text {sat }}\right)$ and gate threshold voltage were calculated from the derivative and the $x$-axis interception of the $\sqrt{ } I_{D}\left(V_{G}\right)$ plot, respectively. The subthreshold gate swing value $(S)$ was obtained at the maximum slope of $d V_{G} / d\left(\log I_{D}\right)$. Table II presents a comparison of the electrical parameters of the two series of paper-based GIZO FETs and of a typical GIZO FET fabricated on crystalline silicon, using thermal $\mathrm{SiO}_{2}$ as the dielectric layer $(100 \mathrm{~nm})$.

With the exception of the $I_{\mathrm{OFF}}$ current value, which is around four orders of magnitude higher than that of GIZO FETs fabricated using $\mathrm{SiO}_{2}$ as the dielectric layer, the present obtained electronic performances of devices do not significantly differ. The observed difference can be explained by the fact that cellulose fibers have a typically open structure (macroporosity), as can be seen in Fig. 5 .

\section{CONCLUSION}

We have produced high-performance hybrid flexible FETs using cellulose fiber (without any treatment) as the dielectric layer and a semiconductor oxide (GIZO), deposited by RF magnetron sputtering at room temperature, as the channel layer. The transistors processed under this way have an enhancement n-type operation mode and exhibit an near-zero threshold voltage, a channel saturation mobility exceeding $30 \mathrm{~cm}^{2} / \mathrm{Vs}$, a drain-source current $I_{\mathrm{ON}} / I_{\mathrm{OFF}}$ modulation ratio above $10^{4}$, and a subthreshold gate voltage swing of about $0.8 \mathrm{~V} /$ decade.
Even two months after processing the device, performances were unchanged, revealing that they are environmentally stable (stored in air ambient conditions).

The obtained results outpace those of amorphous Si TFTs and rival with the actual state of art concerning oxide-based TFTs produced on either glass or crystalline silicon substrates, even the ones processed or annealed at temperatures as high as $200{ }^{\circ} \mathrm{C}-300{ }^{\circ} \mathrm{C}$.

The compatibility of these devices with large-scale/largearea deposition techniques and low-cost substrates as well as their very low operating bias delineates this as a promising approach to attain high-performance disposable electronics like paper displays, smart labels, smart packaging, RFID, and pointof-care systems for self-analysis in bioapplications, among others.

\section{REFERENCES}

[1] B.-J. de Gans, P. C. Duineveld, and U. S. Schubert, "Inkjet printing of polymers: State of the art and future developments," Adv. Mater, vol. 16, no. 3, pp. 203-213, 2004

[2] M. L. Chabinyc, W. S. Wong, A. C. Arias, S. Ready, R. A. Lujan, J. H. Daniel, B. Krusor, R. B. Apte, A. Salleo, and R. A. Street, "Printing methods and materials for large-area electronic devices," Proc. IEEE, vol. 93, no. 8, pp. 1491-1499, Aug. 2005.

[3] L. Yang, A. Rida, R. Vyas, and M. M. Tentzeris, "RFID tag and RF structures on a paper substrate using inkjet-printing technology," IEEE Trans. Microw. Theory Tech., vol. 55, no. 12, pp. 2894-2901, Dec. 2007.

[4] B. Zimmermann, M. Glatthaar, M. Niggemann, M. K. Riede, A. Hinsch, and A. Gombert, "ITO-free wrap through organic solar cells-A module concept for cost-efficient reel-to-reel production," Sol. Energy Mater. Sol. Cells, vol. 91, no. 5, pp. 374-378, 2007.

[5] Y.-H. Kim, D.-G. Moon, and J.-I. Han, "Organic TFT array on a paper substrate," IEEE Electron Device Lett., vol. 25, no. 10, pp. 702-704, Oct. 2004.

[6] D. Nilsson, N. Robinson, M. Berggren, and R. Forchheimer, "Electrochemical logic circuits," Adv. Mater, vol. 17, no. 3, pp. 353-358, 2005.

[7] P. Andersson, D. Nilsson, P.-O. Svensson, M. Chen, A. Malmstrom, T. Remonen, T. Kugler, and M. Berggren, "Active matrix displays based on all-organic electrochemical smart pixels printed on paper," Adv. Mater., vol. 14, no. 20, pp. 1460-1464, 2002.

[8] V. L. Pushparaj, M. M. Shaijumon, A. Kumar, S. Murugesan, L. Ci, R. Vajtai, R. J. Linhardt, O. Nalamasu, and P. M. Ajayan, "Flexible energy storage devices based on nanocomposite paper," in Proc. PNAS, 2007, vol. 104, p. 13574.

[9] A. Henzen and J. van de Kamer, "The present and future of electronic paper," J. Soc. Inf. Disp., vol. 14, no. 5, pp. 437-442, May 2006.

[10] E. M. C. Fortunato, P. M. C. Barquinha, A. Pimentel, A. M. F. Goncalves, A. J. S. Marques, L. M. N. Pereira, and R. F. P. Martins, "Fully transparent $\mathrm{ZnO}$ thin-film transistor produced at room temperature," Adv. Mater. vol. 17, no. 5, pp. 590-594, 2005.

[11] E. Fortunato, P. Barquinha, G. Gonçalves, L. Pereira, and R. Martins, "High mobility and low threshold voltage transparent thin film transistors based on amorphous indium zinc oxide semiconductors," Solid-State Electron., vol. 52, no. 3, pp. 443-448, Mar. 2008.

[12] P. Barquinha, A. Vilà, G. Gonçalves, L. Pereira, R. Martins, J. Morante, and E. Fortunato, "Gallium-indium-zinc-oxide based thin-film transistors: Influence of the source/drain material," IEEE Trans. Electron Devices, vol. 55, no. 7, pp. 954-960, Apr. 2008.

[13] E. Fortunato, A. Goncalves, V. Assuncao et al., "Growth of $\mathrm{ZnO}: \mathrm{Ga}$ thin films at room temperature on polymeric substrates: Thickness dependence," Thin Solid Films, vol. 442, no. 1, p. 121, Oct. 2003. 